\title{
Measurement of Some Special Parameters of Engines
}

\author{
P.A. Lakshminarayanan
}

\begin{abstract}
The subject of reciprocating engines revolves around efficient combustion with emissions lower than legal limits and transferring the power safely to the shaft. Engineers work with various models for combustion and power train. However, we understand only about $80 \%$ of what happens inside the engine even when advanced simulation techniques based on multi-physics is carried out. To verify or improve combustion in the engine, various parameters are to be measured either at steady or at transient states. In this lecture, we are presenting measurement of some important parameters namely airflow, egr flow, combustion performance, and ammonia.
\end{abstract}

Keywords Engine parameters - Reciprocating engine - Combustion performance and ammonia $\cdot$ Simulation technique $\cdot$ Airflow $\cdot$ Egr flow etc.

P.A. Lakshminarayanan ( $\square)$

Simpson \& Co. Ltd, Chennai, India

e-mail: pal@simpson.co.in 